\title{
Immuno-PET of Tissue Factor in Pancreatic Cancer
}

\author{
Hao Hong ${ }^{1}$, Yin Zhang ${ }^{2}$, Tapas R. Nayak ${ }^{1}$, Jonathan W. Engle ${ }^{2}$, Hing C. Wong ${ }^{3}$, Bai Liu ${ }^{3}$, Todd E. Barnhart ${ }^{2}$, and \\ Weibo Cai ${ }^{1,2,4}$ \\ ${ }^{1}$ Department of Radiology, University of Wisconsin, Madison, Wisconsin; ${ }^{2}$ Department of Medical Physics, University \\ of Wisconsin, Madison, Wisconsin; ${ }^{3}$ Altor BioScience Corp., Miramar, Florida; and ${ }^{4}$ Carbone Cancer Center, \\ University of Wisconsin, Madison, Wisconsin
}

\begin{abstract}
Upregulation of tissue factor (TF) expression leads to increased patient morbidity and mortality in many solid tumor types. The goal of this study was to develop a PET tracer for imaging of TF expression in pancreatic cancer. Methods: ALT-836, a chimeric antihuman TF monoclonal antibody, was conjugated to 2-S-(4isothiocyanatobenzyl)-1,4,7-triazacyclononane-1,4,7-triacetic acid ( $p$-SCN-Bn-NOTA) and labeled with ${ }^{64} \mathrm{Cu}$. To compare the TF binding affinity of ALT-836 and NOTA-ALT-836, flow cytometry analysis was performed in 3 pancreatic cancer cell lines with different expression levels of TF (from low to high: PANC-1, ASPC-1, and BXPC-3). PET, biodistribution, blocking, and histology studies were performed on pancreatic tumor-bearing mice to evaluate the ability and specificity of ${ }^{64} \mathrm{Cu}-\mathrm{NOTA}-\mathrm{ALT}-$ 836 to target TF in vivo. Results: There was no difference in TF binding affinity between ALT-836 and NOTA-ALT-836. ${ }^{64} \mathrm{Cu}-$ labeling was achieved with high yield and specific activity. Serial PET revealed that the uptake of ${ }^{64} \mathrm{Cu}-\mathrm{NOTA}-\mathrm{ALT}-836$ in BXPC-3 tumors (high TF expression) was $5.7 \pm 1.8,10.4 \pm 0.8$, and $16.5 \pm 2.6$ percentage injected dose per gram at 4,24 , and $48 \mathrm{~h}$ after injection, respectively $(n=4)$, significantly higher than that in the PANC-1 and ASPC-1 tumors. Biodistribution data as measured by $\gamma$-counting were consistent with the PET findings. Blocking experiments and histology further confirmed the TF specificity of ${ }^{64} \mathrm{Cu}-\mathrm{NOTA}-\mathrm{ALT}-836$. Conclusion: Herein we report the first successful PET imaging of TF expression. Persistent and TF-specific uptake of ${ }^{64} \mathrm{Cu}$-NOTA-ALT-836 was observed in pancreatic cancer models.
\end{abstract}

Key Words: tissue factor (TF); pancreatic cancer; positron emission tomography (PET); monoclonal antibody; ${ }^{64} \mathrm{Cu}$; immuno-PET

J Nucl Med 2012; 53:1748-1754

DOI: 10.2967/jnumed.112.105460

$\mathbf{T}$ issue factor (TF), also known as platelet tissue factor, factor III, thrombokinase, or CD142, is a 47-kDa transmembrane glycoprotein receptor present in subendothelial tissue, platelets, and leukocytes ( 1 ). The principal function of TF is to localize the coagulation serine protease factor VII/VIIa to

\footnotetext{
Received Mar. 2, 2012; revision accepted May 31, 2012.

For correspondence or reprints contact: Weibo Cai, Departments of Radiology and Medical Physics, University of Wisconsin-Madison, Room

7137, 1111 Highland Ave., Madison, WI 53705-2275.

E-mail: wcai@uwhealth.org

Published online Sep. 17, 2012.

COPYRIGHT (C) 2012 by the Society of Nuclear Medicine and Molecular Imaging, Inc.
}

the cell surface, thereby initiating the coagulation cascade. In normal human tissues, TF is expressed only in extravascular cells that comprise the vascular adventitia and organ capsules, forming a hemostatic barrier surrounding the vasculature to prevent blood loss (2). Damages to the endothelial lining of blood vessels can lead to the initiation of TF expression, which ultimately results in activation of the coagulation system (3). The expression of TF is upregulated in several scenarios such as thrombosis, tumor growth, metastasis, and angiogenesis $(4,5)$. Clinically, the pathologic consequences of unregulated activation of the coagulation system are a major cause of increased morbidity and mortality in cancer patients (6).

With about 44,030 estimated new cases and 37,660 estimated deaths in 2011 in the United States, pancreatic cancer is among the most incurable of malignant diseases, with a dismal 5-y survival rate of about 5\% (7). Most pancreatic adenocarcinoma has been found to be associated with several hemostatic complications such as venous and arterial thrombosis, migratory thrombophlebitis, pulmonary embolism, disseminated intravascular coagulation, and simultaneously aggressive tumor angiogenesis and metastasis $(8,9)$. It is now generally recognized that a strong correlation exists between the aberrant expression of TF and pancreatic cancer $(10,11)$, as well as many other solid tumor types such as breast cancer (4), glioma (12), leukemia (13), and lung cancer (14). This correlation signifies the potential not only for inhibiting tumor angiogenesis/metastasis and the associated thrombosis through modulation of TF signaling but also for using TF as a prognostic marker (15).

ALT-836 (formerly known as Sunol-cH36) is a chimeric antihuman TF monoclonal antibody that binds to the factor $\mathrm{X}$ (FX)-binding site in TF with subnanomolar affinity, which can block the activation of FX and inhibit the coagulation cascade (16). ALT-836 did not exhibit a significant effect on TF-initiated clotting times in assays using plasma and lipidated TF from mice, indicating low binding affinity of ALT-836 to murine TF. Recently, ALT- 836 has been evaluated in a phase 1 clinical trial in acute lung injury/acute respiratory distress syndrome (ALI/ARDS) (17). Based on the encouraging phase I results, a phase II clinical trial is currently ongoing. In addition, ALT-836 is in a phase I clinical trial for locally advanced or metastatic solid tumors. 
PET has been widely used in clinical oncology for tumor staging and for monitoring therapeutic efficacy (18-21). Although anti-TF antibodies have been used for imaging of thrombus formation and atherosclerotic plaques in animal models $(22,23)$, no PET study of TF has been reported to date. The goal of this proof-of-principle study was to investigate whether ALT-836 can be used for PET imaging of TF in preclinical pancreatic cancer models, using ${ }^{64} \mathrm{Cu}$ as the radiolabel, which can open new avenues for future patient selection and stratification in TF-related clinical trials, as well as for monitoring therapeutic response. Various in vitro, in vivo, and ex vivo studies were performed to validate the PET findings by confirming the TF specificity of ${ }^{64} \mathrm{Cu}$-labeled ALT-836.

\section{MATERIALS AND METHODS}

\section{Chemicals}

ALT-836 was provided by Altor Bioscience Corp. Alexa Fluor 488 and Cy3-labeled secondary antibodies were purchased from Jackson Immunoresearch Laboratories, Inc. S-2-(4-isothiocyanatobenzyl)1,4,7-triazacyclononane-1,4,7-triacetic acid ( $p$-SCN-Bn-NOTA) and Chelex 100 resin (50-100 mesh) were purchased from Macrocyclics, Inc., and Sigma-Aldrich, respectively. ${ }^{64} \mathrm{Cu}$ was produced using the ${ }^{64} \mathrm{Ni}(\mathrm{p}, \mathrm{n}){ }^{64} \mathrm{Cu}$ reaction with a cyclotron. Water and all buffers were of Millipore grade and pretreated with Chelex 100 resin to ensure that the aqueous solution was free of heavy metals. All other reaction buffers and chemicals were from Thermo Fisher Scientific.

\section{Cell Lines and Animal Models}

BXPC-3, ASPC-1, and PANC-1 pancreatic cancer cell lines were purchased from the American Type Culture Collection and cultured according to the supplier's instructions. Cells were used for in vitro and in vivo experiments when they reached approximately $75 \%$ confluence. All animal studies were conducted under a protocol approved by the University of Wisconsin Institutional Animal Care and Use Committee. Four- to 5-wk-old female athymic nude mice were purchased from Harlan, and tumors were established by subcutaneously injecting $5 \times 10^{6}$ cells—suspended in $100 \mu \mathrm{L}$ of a 1:1 mixture of culture medium and Matrigel (BD Biosciences) - into the front flank of mice. Mice were used for in vivo experiments when the diameter of the tumors reached 5-8 $\mathrm{mm}$ (4-6 wk after inoculation).

\section{Antibody Conjugation and Radiolabeling}

NOTA-ALT-836 was prepared using a method similar to one previously described (24), with the reaction ratio of $p$-SCN-BnNOTA:ALT-836 being $25: 1 .{ }^{64} \mathrm{Cu}$ labeling and purification were also performed using a method similar to the one previously described (24), with $37 \mathrm{MBq}$ of ${ }^{64} \mathrm{Cu}$ per $25 \mu \mathrm{g}$ of NOTA-ALT-836.

\section{Flow Cytometry}

The TF binding activities of ALT-836 and NOTA-ALT-836 to BXPC-3, ASPC-1, and PANC-1 cells were evaluated by flow cytometry. Briefly, cells were harvested and suspended in cold phosphate-buffered saline with $2 \%$ bovine serum albumin at a concentration of $5 \times 10^{6}$ cells $/ \mathrm{mL}$. The cells were incubated with ALT-836 or NOTA-ALT-836 (1 or $5 \mu \mathrm{g} / \mathrm{mL}$ ) for $30 \mathrm{~min}$ at room temperature, washed 3 times with cold phosphate-buffered saline, and centrifuged at 1,000 rpm for $5 \mathrm{~min}$. The cells were then incubated with Alexa Fluor 488-labeled goat antihuman IgG for $30 \mathrm{~min}$ at room temperature. Afterward, the cells were washed and analyzed using a FACSCalibur 4-color analysis cytometer (BectonDickinson) with FlowJo analysis software (Tree Star, Inc.).

\section{PET/CT and Biodistribution Studies}

PET and CT scans, image reconstruction, and region-of-interest analysis of the PET data were performed using an Inveon microPET/microCT rodent model scanner (Siemens Medical Solutions USA, Inc.) as described earlier $(24,25)$. Each tumor-bearing mouse was injected with $5-10 \mathrm{MBq}$ of ${ }^{64} \mathrm{Cu}-\mathrm{NOTA}-\mathrm{ALT}-836$ via the tail vein, and 5- to 10-min static PET scans were obtained at various time points after injection. Tracer uptake was presented as percentage injected dose per gram of tissue $(\% \mathrm{ID} / \mathrm{g}$ ) (mean $\pm \mathrm{SD}$; 4 mice per group). Each mouse of another group of 4 BXPC-3 tumorbearing mice was injected with $1 \mathrm{mg}$ of unlabeled ALT-836 at $2 \mathrm{~h}$ before ${ }^{64} \mathrm{Cu}$-NOTA-ALT-836 administration to evaluate the TF specificity of the tracer in vivo (i.e., blocking experiment). Biodistribution studies were performed after the last PET scans at $48 \mathrm{~h}$ after injection to validate the PET data. The tumors, liver, spleen (i.e., tissues with significant uptake of ${ }^{64} \mathrm{Cu}$-NOTA-ALT-836), and muscle were also frozen and cryosectioned for histologic analysis.

\section{Histology}

Frozen tissue slices of $5-\mu \mathrm{m}$ thickness were fixed with cold acetone for $10 \mathrm{~min}$ and dried in the air for $30 \mathrm{~min}$. After rinsing with phosphate-buffered saline and blocking with $10 \%$ donkey serum for $30 \mathrm{~min}$ at room temperature, the slices were incubated with ALT-836 $(2 \mu \mathrm{g} / \mathrm{mL})$ for $1 \mathrm{~h}$ at $4^{\circ} \mathrm{C}$ and visualized using Alexa Fluor 488-labeled goat antihuman IgG. The tissue slices were also stained for endothelial marker CD31 as described previously (26,27). After washing with phosphate-buffered saline, the slices were incubated with rat antimouse CD31 antibody $(2 \mu \mathrm{g} / \mathrm{mL})$ for $1 \mathrm{~h}$, followed by Cy3-labeled donkey antirat IgG for $30 \mathrm{~min}$. All images were acquired with an Eclipse Ti microscope (Nikon).

\section{Statistical Analysis}

Quantitative data were expressed as mean \pm SD. Means were compared using the Student $t$ test. $P$ values of less than 0.05 were considered statistically significant.

\section{RESULTS}

\section{Characterization of NOTA-ALT-836}

Based on flow cytometry analysis of both BXPC-3 and ASPC- 1 cells (high and medium TF expression, respectively (15)), there were no observable differences between ALT-836 and NOTA-ALT-836 at 1 or $5 \mu \mathrm{g} / \mathrm{mL}$ (Fig. 1). For PANC-1 cells, which are TF-negative (15), neither ALT-836 nor NOTAALT-836 bound to the cells at these concentrations. Together, these results indicated that NOTA conjugation did not alter the antigen-binding affinity or specificity of ALT836, with little nonspecific binding in cell culture. Furthermore, the binding level of ALT-836 and NOTA-ALT-836 to the 3 cell lines was in accordance with TF expression level in these cells (BXPC-3 > ASPC-1 > PANC-1).

\section{Radiochemistry}

${ }^{64} \mathrm{Cu}$-labeling, including final purification using PD-10 columns, took $70 \pm 10 \mathrm{~min}(n=6)$. The decay-corrected radiochemical yield was $79.6 \% \pm 5.4 \%$, based on $25 \mu \mathrm{g}$ of 


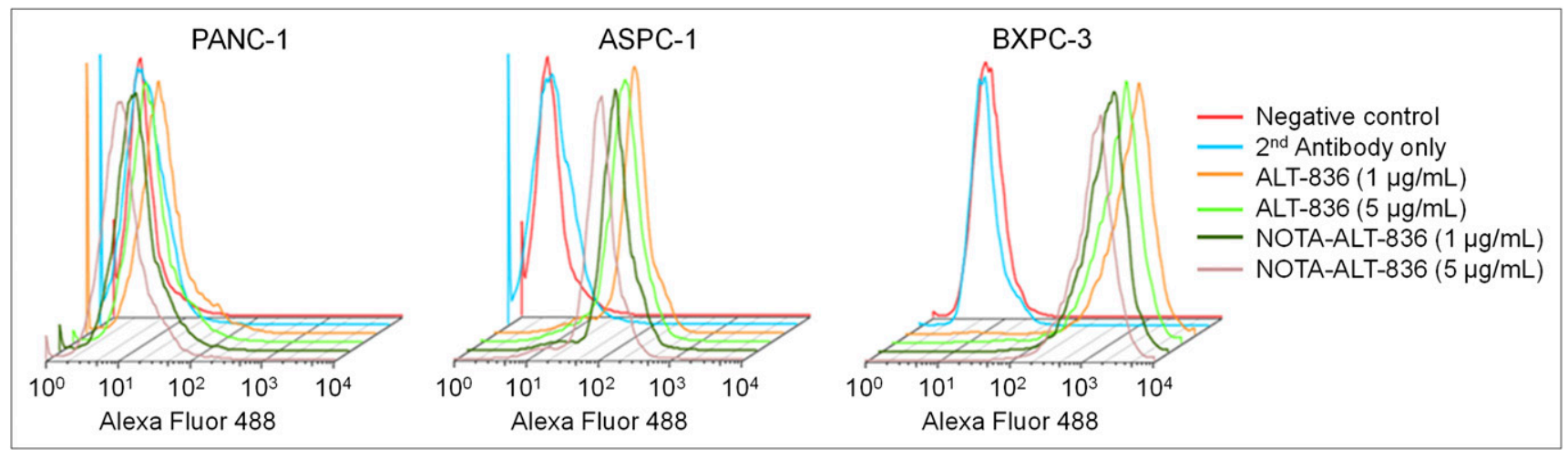

FIGURE 1. Flow cytometry analysis of various concentrations of ALT-836 and NOTA-ALT-836 in 3 pancreatic cancer cell lines: PANC-1 (TF-negative), ASPC-1 (medium TF expression), and BXPC-3 (high TF expression).

NOTA-ALT-836 per $37 \mathrm{MBq}$ of ${ }^{64} \mathrm{Cu}$, with radiochemical purity greater than $95 \%$. The ratio of ${ }^{64} \mathrm{Cu}$ activity to antibody mass was $1.2 \mathrm{GBq} / \mathrm{mg}(4.86 \mathrm{Ci} / \mu \mathrm{mol})$, assuming complete antibody recovery after size-exclusion chromatography.

\section{PET}

Time points of 4, 24, and $48 \mathrm{~h}$ after injection, based on the half-life of ${ }^{64} \mathrm{Cu}(12.7 \mathrm{~h})$, were chosen for serial PET scans after intravenous injection of ${ }^{64} \mathrm{Cu}$-NOTA-ALT-836 into tumor-bearing mice. The coronal slices that contained the tumors are shown in Figure 2A, and representative PET/CT images of a BXPC-3 tumor-bearing mouse at $24 \mathrm{~h}$ after injection are shown in Figure 2B. The quantitative data obtained from region-of-interest analysis are shown in Figure 3.

Liver uptake and blood-pool activity of ${ }^{64} \mathrm{Cu}$-NOTA-ALT836 were prominent at early time points and gradually declined over time, similarly to other radiolabeled antibodies reported in the literature. In the PANC-1 tumor, which does not express a detectable level of TF, the uptake of ${ }^{64} \mathrm{Cu}-$ NOTA-ALT-836 was low $(1.7 \pm 0.8,2.8 \pm 0.7$, and $2.2 \pm$ $0.6 \% \mathrm{ID} / \mathrm{g}$ at 4,24 , and $48 \mathrm{~h}$ after injection, respectively; $n=$ 4; Figs. 2A and 3A). The liver uptake (18.2 $\pm 1.8,16.7 \pm$ 1.4 , and $10.2 \pm 0.9 \% \mathrm{ID} / \mathrm{g}$ at 4,24 , and $48 \mathrm{~h}$ after injection, respectively) and blood radioactivity (10.6 $\pm 1.3,6.8 \pm 1.5$, and $3.5 \pm 0.7 \% \mathrm{ID} / \mathrm{g}$ at 4,24 , and $48 \mathrm{~h}$ after injection, respectively; $n=4$; Figs. $2 \mathrm{~A}$ and $3 \mathrm{~A}$ ) were similar to those in the other 2 tumor models. Uptake of ${ }^{64} \mathrm{Cu}$-NOTA-ALT-836 in the ASPC-1 tumors (medium TF expression) was higher than that in the PANC-1 tumors, at $2.1 \pm 0.7,4.6 \pm 0.8$, and $5.3 \pm 0.9 \% \mathrm{ID} / \mathrm{g}$ at 4,24 , and $48 \mathrm{~h}$ after injection, respectively ( $n=4$; Figs. 2A and 3B). In BXPC-3 tumor-bearing mice, tumor uptake of ${ }^{64} \mathrm{Cu}$-NOTA-ALT-836 was clearly visible as early as $4 \mathrm{~h}$ after injection and increased over time $(5.7 \pm 1.8,10.4 \pm 0.8$, and $16.5 \pm 2.6 \% \mathrm{ID} / \mathrm{g}$ at 4,24 , and $48 \mathrm{~h}$ after injection, respectively; $n=4$; Figs. $2 \mathrm{~A}$ and $3 \mathrm{C})$. These values were significantly higher than those of the PANC-1 and ASPC-1 tumors at all time points $(P<$ 0.05 ), indicating $\mathrm{TF}$ specificity of the tracer.

Administration of a blocking dose of ALT- 836 at $2 \mathrm{~h}$ before ${ }^{64} \mathrm{Cu}$-NOTA-ALT-836 injection reduced the tumor uptake to $0.7 \pm 0.4,2.3 \pm 0.9$, and $2.8 \pm 0.7 \% \mathrm{ID} / \mathrm{g}$ at
4,24 , and $48 \mathrm{~h}$ after injection, respectively $(n=4$; Figs. $2 \mathrm{~A}$ and 3D), which was significantly different from that of mice injected with ${ }^{64} \mathrm{Cu}$-NOTA-ALT-836 alone $(P<0.05$ at all 3 time points). Slightly higher radioactivity in the blood was observed at early time points $(12.4 \pm 0.5$ and $6.9 \pm 2.1$ $\% \mathrm{ID} / \mathrm{g}$ at 4 and $24 \mathrm{~h}$ after injection, respectively; $n=4$; Fig. 3D) in the blocking group, whereas liver uptake of ${ }^{64} \mathrm{Cu}-$ NOTA-ALT-836 $(15.6 \pm 0.4,12.8 \pm 0.3$, and $10.5 \pm 0.6$ $\% \mathrm{ID} / \mathrm{g}$ at 4,24 , and $48 \mathrm{~h}$ after injection, respectively; $n=4$; Fig. 3D) was comparable to that of mice injected with ${ }^{64} \mathrm{Cu}-$ NOTA-ALT-836 alone. Overall, tracer uptake in all major organs was similar between the 2 groups, yet the BXPC- 3 tumor uptake was significantly higher in the ${ }^{64} \mathrm{Cu}$-NOTAALT-836-dosed mice than in the blocking group, confirming the TF specificity of the tracer in vivo.

An additional group of 3 mice was injected with PANC-1 cells on the left flank and BXPC-3 cells on the right flank and subjected to serial ${ }^{64} \mathrm{Cu}-\mathrm{NOTA}-\mathrm{ALT}-836$ PET scans. Since BXPC-3 tumors grow faster than PANC-1 tumors, the tumor diameters at the time of the PET scans were about $7 \mathrm{~mm}$ for BXPC-3 and about $4 \mathrm{~mm}$ for PANC-1. Significant uptake of ${ }^{64} \mathrm{Cu}-\mathrm{NOTA}-\mathrm{ALT}-836$ in the BXPC-3 tumors could be observed at $24 \mathrm{~h}$ and $48 \mathrm{~h}$ after injection, whereas tracer uptake in the PANC-1 tumors was at the background level (Fig. 3E). Noninvasive detection of TF-positive tumors but not TF-negative tumors in the same mice further validated that ${ }^{64} \mathrm{Cu}-\mathrm{NOTA}-\mathrm{ALT}-836$ can specifically target TF in vivo.

\section{Biodistribution Studies}

All mice were euthanized after the terminal PET scans at $48 \mathrm{~h}$ after injection for biodistribution and histology studies to validate the in vivo PET data. Besides the tumors, the blood, liver, and spleen also had a significant accumulation of radioactivity at $48 \mathrm{~h}$ after injection, as expected for a radiolabeled antibody that typically has a long circulation halflife and hepatic clearance (Fig. 4A). Appreciable kidney uptake $(\sim 5 \% \mathrm{ID} / \mathrm{g})$ was also observed, likely due to a small fraction of ${ }^{64} \mathrm{Cu}$ detaching from NOTA-ALT-836 and degradation of the tracer over time (lower-molecular-weight species can undergo renal clearance). ${ }^{64} \mathrm{Cu}-\mathrm{NOTA}-\mathrm{ALT}-836$ showed a similar biodistribution profile in BXPC-3, ASPC-1, and 


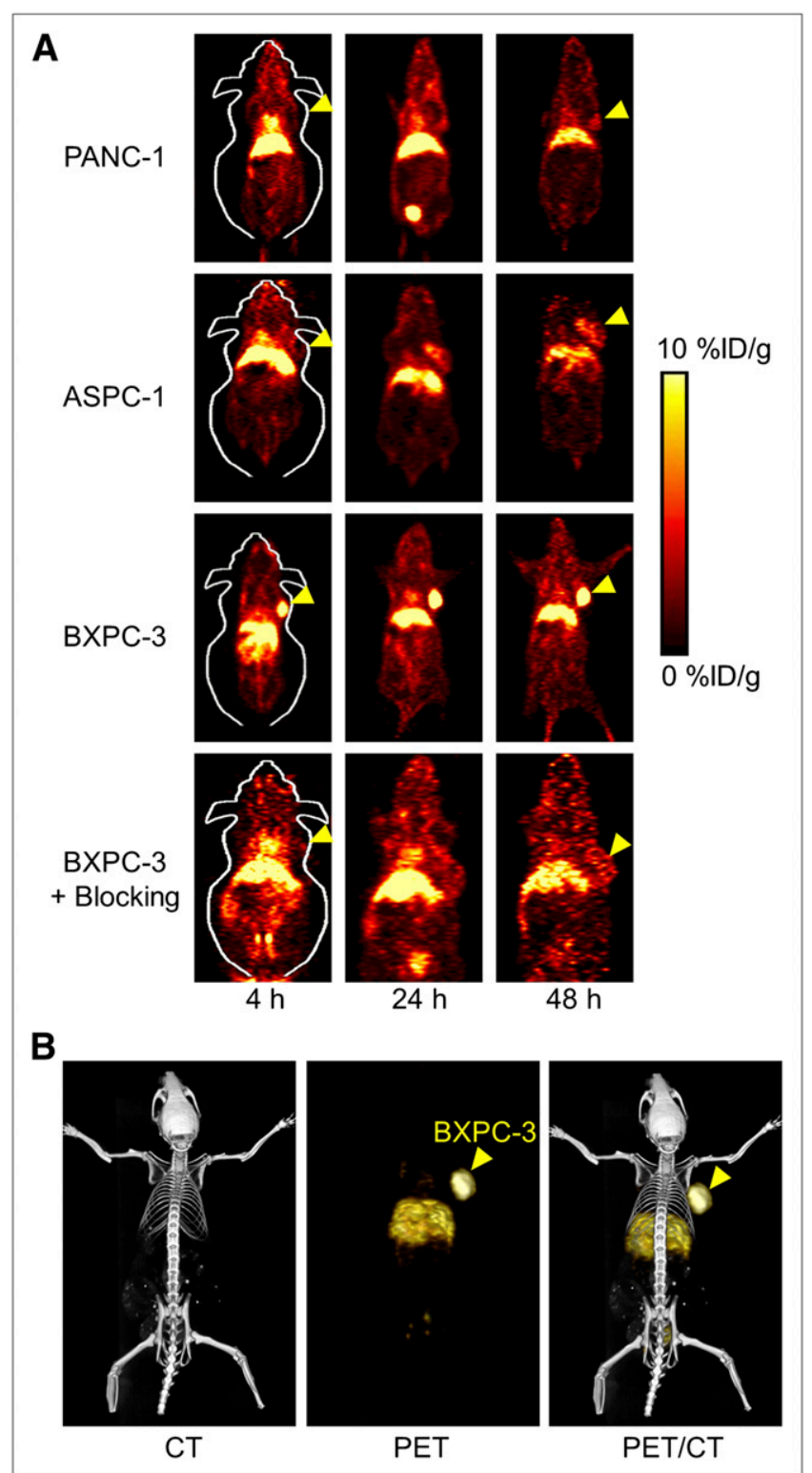

FIGURE 2. Small-animal PET of TF in pancreatic tumor-bearing mice. (A) Serial coronal PET images at 4, 24, and $48 \mathrm{~h}$ after injection of ${ }^{64} \mathrm{Cu}-\mathrm{NOTA}-\mathrm{ALT}-836$ (all 3 tumor models) or $1 \mathrm{mg}$ of ALT-836 before ${ }^{64} \mathrm{Cu}-\mathrm{NOTA}-\mathrm{ALT}-836$ (i.e., blocking, BXPC-3 only). Tumors are indicated by arrowheads. (B) Representative PET/CT images of ${ }^{64} \mathrm{Cu}-\mathrm{NOTA}$-ALT-836 in BXPC-3 tumor-bearing mice at $24 \mathrm{~h}$ after injection.

PANC-1 tumor-bearing mice in all the major organs and tissues except the tumor. When compared with all major organs in mice, BXPC- 3 tumor uptake of ${ }^{64} \mathrm{Cu}$-NOTA-ALT836 was the highest and provided excellent tumor contrast, with a tumor-to-muscle ratio of $24.2 \pm 2.1$ at $48 \mathrm{~h}$ after injection $(n=4)$.

Preinjection of a blocking dose of ALT- 836 led to a significantly decreased uptake in BXPC-3 tumor $(P<0.01$; $n=4$; Fig. 4B) but not in other normal tissues including the blood and liver, corroborating the PET findings. Overall, consistent quantitative data from ex vivo biodistribution studies and in vivo PET scans demonstrated that region-of-interest analysis of noninvasive PET scans accurately reflected tracer distribution in vivo, as well as TF specificity of ${ }^{64} \mathrm{Cu}-\mathrm{NOTA}-$ ALT-836.

\section{Histology}

Immunofluorescence TF/CD31 staining revealed that $\mathrm{TF}$ expression was prominent on the BXPC-3/ASPC-1 tumor cells but absent on the PANC-1 cells (Fig. 5). TF staining of mouse liver, spleen, and muscle gave a low signal, since not only do these tissues not express TF at a high level, but also the binding affinity of ALT-836 to murine TF is low. Therefore, uptake of ${ }^{64} \mathrm{Cu}$-NOTA-ALT-836 in mouse liver and spleen was largely unrelated to TF binding and more likely related to nonspecific capture by the reticuloendothelial system and hepatic clearance of the tracer.

\section{DISCUSSION}

$\mathrm{TF}$ is overexpressed in most cancer types $(28,29)$. Mounting literature data have suggested a key role for TF in the development of cancer-associated thrombosis and tumor growth, angiogenesis, and metastasis. As a direct antagonist of TF, ALT-836 can be used to block TF signaling in cancer, thereby inhibiting cancer-associated venous thromboembolism and tumor development and metastasis. In preclinical studies including nonhuman primates, ALT836 exhibited potent antithrombotic and antiinflammatory activities with a good safety profile (16). In patients with coronary artery disease and ALI/ARDS, single-dose administration of ALT-836 was found to be safe and exhibited anticoagulant and antiinflammatory effects (17). A phase II study using a multidose regimen of ALT-836 is being conducted in patients with ALI/ARDS.

With these encouraging results, a phase I, open-label, multicenter, dose-escalation study of ALT-836 in combination with gemcitabine for locally advanced or metastatic solid tumors is currently ongoing, with the primary outcome measures being maximum tolerated dose of ALT-836 in combination with gemcitabine, safety profile, number and severity of treatment-related adverse effects, clinical benefit, progression-free survival, and others (ClinicalTrials.gov identifier, NCT01325558). The development of a PET tracer based on ALT-836, which does not affect its binding affinity and specificity to TF, can play multiple roles in future clinical trials of ALT-836 such as patient selection, which can significantly improve the response rate in cancer patients. In addition, radiolabeled ALT- 836 can be used to more effectively study the pharmacokinetics of this antibody, as well as to monitor the therapeutic effect of drugs that act through modulation of $\mathrm{TF}$ signaling.

Pancreatic cancer is the fourth leading cause of cancer death in the United States (30). With a 5-y survival rate of about $5 \%$ and a median survival of less than 6 mo, the diagnosis of pancreatic cancer carries one of the most dismal prognoses. Because of the lack of specific symptoms and limitations in diagnostic methods, pancreatic cancer is 
FIGURE 3. Quantitative analysis of PET data. (A) Time-activity curves of PANC-1 tumor, liver, blood, and muscle after intravenous injection of ${ }^{64} \mathrm{Cu}$-NOTA-ALT-836 $(n=$ 4). (B) Time-activity curves of ASPC-1 tumor, liver, blood, and muscle after intravenous injection of ${ }^{64} \mathrm{Cu}$-NOTA-ALT-836 $(n=$ 4). (C) Time-activity curves of BXPC-3 tumor, liver, blood, and muscle after intravenous injection of ${ }^{64} \mathrm{Cu}$-NOTA-ALT-836 $(n=$ 4). (D) Time-activity curves of BXPC-3 tumor, liver, blood, and muscle after intravenous injection of ${ }^{64} \mathrm{Cu}$-NOTA-ALT-836 with preinjected blocking dose of ALT-836 ( $n=$ 4). (E) Representative serial coronal PET images at 4,24 , and $48 \mathrm{~h}$ after injection of ${ }^{64} \mathrm{Cu}$-NOTA-ALT-836 in mice bearing both PANC-1 and BXPC-3 tumors.

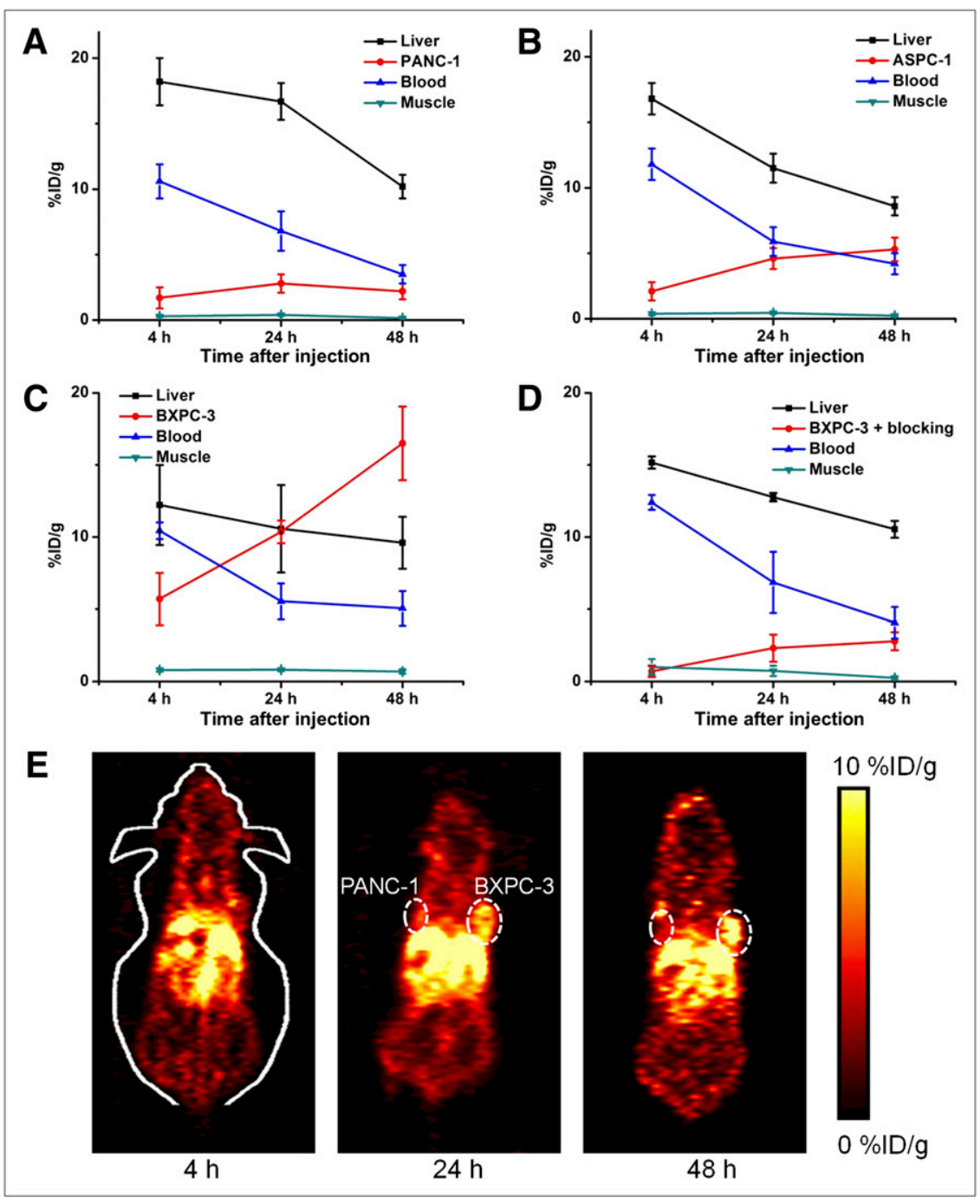

nearly undetectable during its formative stages. Many pancreatic cancer cells are naturally resistant to current chemotherapy and radiation therapy, and to date, most known pancreatic cancer antigens have generated a relatively weak immune response $(30,31)$. Early detection methods are under development but do not yet exist for pancreatic cancer. The correlation between TF and pancreatic cancer development and metastasis makes TF a useful marker for diagnosis (10), and the development of a PET tracer for TF imaging is of critical importance.

To the best of our knowledge, imaging of TF in cancer has not been reported to date. Over the last decade, a myriad of preclinical and clinical data have suggested a promising future for immuno-PET in the management of cancer patients (32). In this study, we have successfully developed and characterized ${ }^{64} \mathrm{Cu}$-labeled ALT-836 for PET imaging of tumor TF expression in vivo. Our data showed that ${ }^{64} \mathrm{Cu}-$ NOTA-ALT-836 specifically bound to TF-positive BXPC-3 tumors but not to TF-negative PANC-1 tumors, and the tumor uptake of ${ }^{64} \mathrm{Cu}$-NOTA-ALT-836 was closely associated with TF expression level in the tumor. Even within the same mouse, ${ }^{64} \mathrm{Cu}$-NOTA-ALT-836 can delineate and differentiate tumors with different TF expression (BXPC-3 vs. PANC-1, Fig. 3E). Such TF specificity in vivo makes ${ }^{64} \mathrm{Cu}-\mathrm{NOTA}-$ ALT-836 a PET tracer with broad potential applications in many clinical situations, not only in cancer but also in many other diseases where TF plays a key role (e.g., ALI/ARDS). To facilitate future clinical translation, further testing of radiolabeled ALT-836 in orthotopic tumor models will be needed since they have different tumor tissue microenvironments and are more clinically relevant than the subcutaneous models used in this proof-of-principle study.

Because the pancreas is near the liver, tracer uptake may be masked by appreciable signal in the liver. Usually, pancreatic cancer is diagnosed through the presence of metastases (33); therefore, we envision that ${ }^{64} \mathrm{Cu}$-NOTA-ALT-836 may be more useful in the metastatic setting than in initial detection of the primary tumor. Guiding surgery with molecularly targeted fluorescent agents has attracted enormous interest over the last decade (34). Future development of fluorescently labeled ALT-836, which emits in the near-infrared range (700-900 $\mathrm{nm}(24,35))$ and hence has good signal pen- 


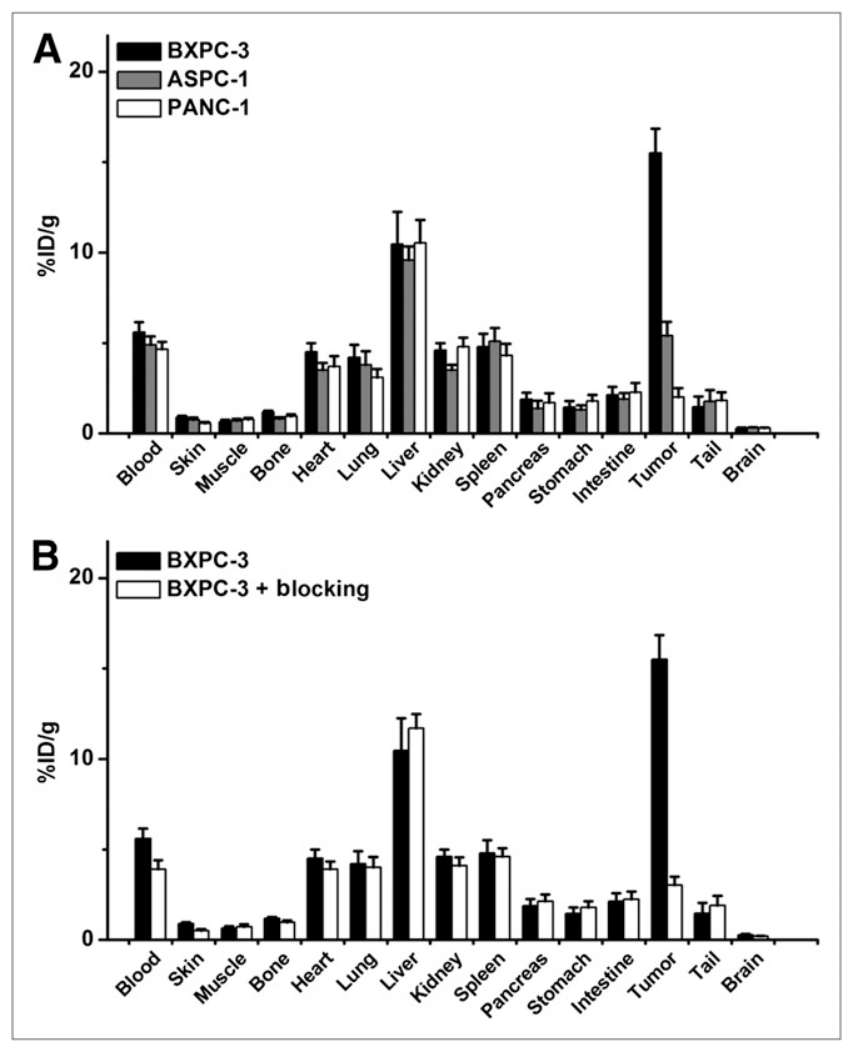

FIGURE 4. Biodistribution studies in pancreatic tumor-bearing mice. (A) Biodistribution of ${ }^{64} \mathrm{Cu}$-NOTA-ALT-836 at $48 \mathrm{~h}$ after injection in 3 pancreatic cancer models $(n=4)$. Tracer uptake in BXPC-3 tumor was significantly higher than that in PANC-1 and ASPC-1 tumors. (B) Biodistribution of ${ }^{64} \mathrm{Cu}-\mathrm{NOTA}-\mathrm{ALT}-836$ at $48 \mathrm{~h}$ after injection in BXPC-3 tumor model, with and without blocking dose of ALT-836 $(n=4)$. Tumor uptake was significantly different between the 2 groups.

etration with low autofluorescence background, may be useful for surgical guidance of tumor removal.

The advantages of antibody-based tracers are that they are antigen-specific and have high binding affinity and absolute tumor uptake, making them suitable for internal radiotherapy applications or targeted delivery of anticancer drugs. To provide more insight about the long-term behavior of ALT836 in vivo, other longer-lived isotopes (e.g., ${ }^{89} \mathrm{Zr}$, which has a decay half-life of $3.3 \mathrm{~d}(25)$ ) can be explored in future studies. The major limitations of antibody-based imaging are slow tumor accumulation and high background signal in the reticuloendothelial system, which may be overcome by peptide-, small-molecule-, or antibody fragment-based tracers $(36,37)$. For pancreatic cancer, since the primary metastasis site is also liver, development of TF-targeting PET probes with low liver uptake will be mandatory for a successful clinical translation.

One of the key requirements for accurate PET imaging with ${ }^{64} \mathrm{Cu}$-labeled antibodies is that the tracer should be sufficiently stable during the imaging period, since the PET scanner detects the distribution of ${ }^{64} \mathrm{Cu}$ rather than the antibody itself. It is now generally agreed that NOTA is one of the best chelators for ${ }^{64} \mathrm{Cu}$ labeling. A recent elegant study

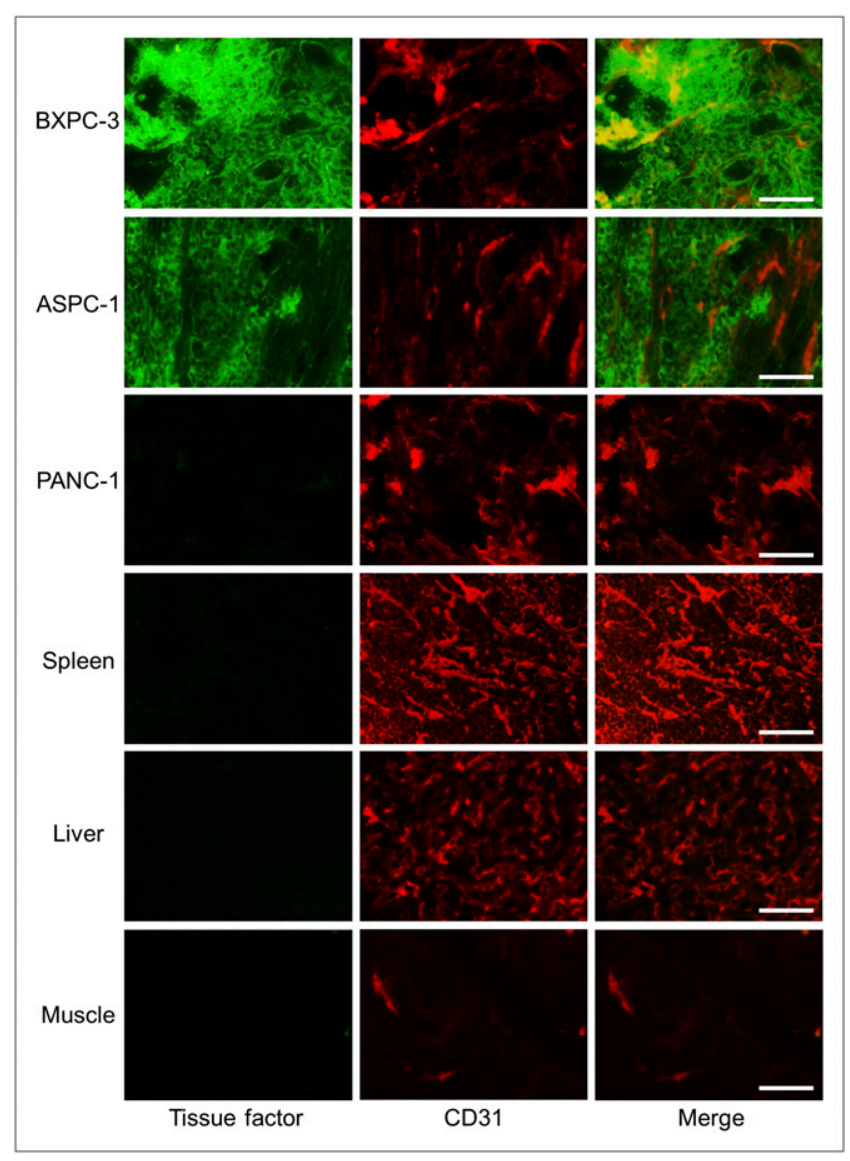

FIGURE 5. Immunofluorescence TF/CD31 double-staining of the 3 pancreatic tumor tissues, spleen, liver, and muscle. ALT-836 and Alexa Fluor 488-labeled goat antihuman IgG was used for TF staining (green). Afterward, tissue slices were stained with rat antimouse CD31 antibody and Cy3-labeled donkey antirat IgG (red). All images were acquired under same conditions and displayed at same scale. Magnification: $\times 200$. Scale bar: $50 \mu \mathrm{m}$.

comparing the effect of several bifunctional chelators on the biodistribution of a ${ }^{64} \mathrm{Cu}$-labeled antibody (38) concluded that thermodynamic stability of ${ }^{64} \mathrm{Cu}$-chelator complexes did not significantly influence tumor uptake of the tracer but dramatically affected distribution in normal tissues. Consistent with this report, our own studies also showed that ${ }^{64} \mathrm{Cu}$-NOTA- and ${ }^{64} \mathrm{Cu}$-DOTA (DOTA denotes 1,4,7,10tetraazacyclododecane-1,4,7,10-tetraacetic acid)-based PET tracers behaved similarly in terms of tumor uptake yet the use of NOTA as the chelator resulted in significantly lower liver uptake $(39,40)$.

\section{CONCLUSION}

Herein we have reported the development, characterization, and in vivo investigation of a ${ }^{64} \mathrm{Cu}$-labeled antibody for PET of TF expression in pancreatic cancer. Rapid, persistent, and TF-specific uptake of ${ }^{64} \mathrm{Cu}$-NOTA-ALT-836 in the BXPC-3 tumor was observed and was further validated by various in vitro, in vivo, and ex vivo experiments. Furthermore, tumor uptake of ${ }^{64} \mathrm{Cu}-\mathrm{NOTA}-\mathrm{ALT}-836$ in vari- 
ous pancreatic tumors was related to their TF expression level. On further optimization and development, such TF-targeted PET tracers can be translated into the clinic for improving the management of pancreatic cancer patients. Lastly, these tracers can also play multiple roles not only in many other solid tumors types but also in many other diseases for which TF signaling is upregulated.

\section{DISCLOSURE STATEMENT}

The costs of publication of this article were defrayed in part by the payment of page charges. Therefore, and solely to indicate this fact, this article is hereby marked "advertisement” in accordance with 18 USC section 1734.

\section{ACKNOWLEDGMENTS}

This work was supported, in part, by the University of Wisconsin Carbone Cancer Center, the Department of Defense (W81XWH-11-1-0644), the National Center for Advancing Translational Sciences (9U54TR000021), and the Elsa U. Pardee Foundation. No other potential conflict of interest relevant to this article was reported.

\section{REFERENCES}

1. Drake TA, Morrissey JH, Edgington TS. Selective cellular expression of tissue factor in human tissues: implications for disorders of hemostasis and thrombosis. Am J Pathol. 1989;134:1087-1097.

2. Nemerson Y. Tissue factor and hemostasis. Blood. 1988;71:1-8.

3. Hobbs JE, Zakarija A, Cundiff DL, et al. Alternatively spliced human tissue factor promotes tumor growth and angiogenesis in a pancreatic cancer tumor model. Thromb Res. 2007;120(suppl 2):S13-S21.

4. Contrino J, Hair G, Kreutzer DL, Rickles FR. In situ detection of tissue factor in vascular endothelial cells: correlation with the malignant phenotype of human breast disease. Nat Med. 1996;2:209-215.

5. Rickles FR, Falanga A. Molecular basis for the relationship between thrombosis and cancer. Thromb Res. 2001;102:V215-V224.

6. Rickles FR, Levine MN. Epidemiology of thrombosis in cancer. Acta Haematol. 2001;106:6-12.

7. Siegel R, Ward E, Brawley O, Jemal A. Cancer statistics, 2011: the impact of eliminating socioeconomic and racial disparities on premature cancer deaths. $C A$ Cancer J Clin. 2011;61:212-236.

8. Khorana AA, Fine RL. Pancreatic cancer and thromboembolic disease. Lancet Oncol. 2004;5:655-663.

9. Hidalgo M. Pancreatic cancer. N Engl J Med. 2010;362:1605-1617.

10. Haas SL, Jesnowski R, Steiner M, et al. Expression of tissue factor in pancreatic adenocarcinoma is associated with activation of coagulation. World J Gastroenterol. 2006;12:4843-4849.

11. van den Berg YW, Osanto S, Reitsma PH, Versteeg HH. The relationship between tissue factor and cancer progression: insights from bench and bedside. Blood. 2012; 119:924-932.

12. Guan M, Jin J, Su B, Liu WW, Lu Y. Tissue factor expression and angiogenesis in human glioma. Clin Biochem. 2002;35:321-325.

13. Hair GA, Padula S, Zeff R, et al. Tissue factor expression in human leukemic cells. Leuk Res. 1996;20:1-11.

14. Koomägi R, Volm M. Tissue-factor expression in human non-small-cell lung carcinoma measured by immunohistochemistry: correlation between tissue factor and angiogenesis. Int J Cancer. 1998;79:19-22.

15. Nitori N, Ino Y, Nakanishi Y, et al. Prognostic significance of tissue factor in pancreatic ductal adenocarcinoma. Clin Cancer Res. 2005;11:2531-2539.
16. Jiao JA, Kelly AB, Marzec UM, et al. Inhibition of acute vascular thrombosis in chimpanzees by an anti-human tissue factor antibody targeting the factor $\mathrm{X}$ binding site. Thromb Haemost. 2010;103:224-233.

17. Morris PE, Steingrub JS, Huang BY, et al. A phase I study evaluating the pharmacokinetics, safety and tolerability of an antibody-based tissue factor antagonist in subjects with acute lung injury or acute respiratory distress syndrome. BMC Pulm Med. 2012;12:5.

18. Gambhir SS, Czernin J, Schwimmer J, Silverman DH, Coleman RE, Phelps ME. A tabulated summary of the FDG PET literature. J Nucl Med. 2001;42(suppl): 1S-93S.

19. Alauddin MM. Positron emission tomography (PET) imaging with ${ }^{18} \mathrm{~F}$-based radiotracers. Am J Nucl Med Mol Imaging. 2012;2:55-76.

20. Vach W, Høilund-Carlsen PF, Fischer BM, Gerke O, Weber W. How to study optimal timing of PET/CT for monitoring of cancer treatment. Am J Nucl Med Mol Imaging. 2011;1:54-62.

21. Grassi I, Nanni C, Allegri V, et al. The clinical use of PET with ${ }^{11} \mathrm{C}$-acetate. Am J Nucl Med Mol Imaging. 2012;2:33-47.

22. Falati S, Gross P, Merrill-Skoloff G, Furie BC, Furie B. Real-time in vivo imaging of platelets, tissue factor and fibrin during arterial thrombus formation in the mouse. Nat Med. 2002;8:1175-1181.

23. Temma T, Ogawa Y, Kuge Y, et al. Tissue factor detection for selectively discriminating unstable plaques in an atherosclerotic rabbit model. J Nucl Med. 2010;51:1979-1986.

24. Zhang Y, Hong H, Engle JW, Yang Y, Barnhart TE, Cai W. Positron emission tomography and near-infrared fluorescence imaging of vascular endothelial growth factor with dual-labeled bevacizumab. Am J Nucl Med Mol Imaging. 2012;2:1-13.

25. Hong H, Severin GW, Yang Y, et al. Positron emission tomography imaging of CD105 expression with ${ }^{89} \mathrm{Zr}$-Df-TRC105. Eur J Nucl Med Mol Imaging. 2012; 39:138-148.

26. Cai W, Chen K, Mohamedali KA, et al. PET of vascular endothelial growth factor receptor expression. J Nucl Med. 2006;47:2048-2056.

27. Cai W, Wu Y, Chen $\mathrm{K}$, Cao Q, Tice DA, Chen X. In vitro and in vivo characterization of ${ }^{64} \mathrm{Cu}$-labeled Abegrin ${ }^{\mathrm{TM}}$, a humanized monoclonal antibody against integrin $\alpha_{\mathrm{v} \beta 33}$. Cancer Res. 2006;66:9673-9681.

28. Milsom C, Magnus N, Meehan B, Al-Nedawi K, Garnier D, Rak J. Tissue factor and cancer stem cells: is there a linkage? Arterioscler Thromb Vasc Biol. 2009; 29:2005-2014.

29. Kasthuri RS, Taubman MB, Mackman N. Role of tissue factor in cancer. J Clin Oncol. 2009;27:4834-4838.

30. Bardeesy N, DePinho RA. Pancreatic cancer biology and genetics. Nat Rev Cancer. 2002;2:897-909.

31. Laheru D, Jaffee EM. Immunotherapy for pancreatic cancer: science driving clinical progress. Nat Rev Cancer. 2005;5:459-467.

32. Wu AM. Antibodies and antimatter: the resurgence of immuno-PET. J Nucl Med. 2009;50:2-5.

33. Asa SL. Pancreatic endocrine tumors. Mod Pathol. 2011;24(suppl 2):S66-S77.

34. van Dam GM, Themelis G, Crane LM, et al. Intraoperative tumor-specific fluorescence imaging in ovarian cancer by folate receptor-alpha targeting: first inhuman results. Nat Med. 2011;17:1315-1319.

35. Yang Y, Zhang Y, Hong H, Liu G, Leigh BR, Cai W. In vivo near-infrared fluorescence imaging of CD105 expression. Eur J Nucl Med Mol Imaging. 2011; 38:2066-2076.

36. Buckle T, van den Berg NS, Kuil J, et al. Non-invasive longitudinal imaging of tumor progression using an ${ }^{111}$ indium labeled CXCR4 peptide antagonist. Am J Nucl Med Mol Imaging. 2012;2:99-109.

37. Hao G, Hajibeigi A, De León-Rodríguez LM, Öz OK, Sun X. Peptoid-based PET imaging of vascular endothelial growth factor receptor (VEGFR) expression. Am J Nucl Med Mol Imaging. 2011;1:65-75.

38. Dearling JL, Voss SD, Dunning P, et al. Imaging cancer using PET: the effect of the bifunctional chelator on the biodistribution of a ${ }^{64} \mathrm{Cu}$-labeled antibody. $\mathrm{Nucl}$ Med Biol. 2011;38:29-38.

39. Hong H, Benink HA, Zhang Y, et al. HaloTag: a novel reporter gene for positron emission tomography. Am J Transl Res. 2011;3:392-403.

40. Zhang Y, Hong H, Engle JW, et al. Positron emission tomography imaging of CD105 expression with a ${ }^{64} \mathrm{Cu}$-labeled monoclonal antibody: NOTA is superior to DOTA. PLoS ONE. 2011;6:e28005. 